\title{
Use of 3DEC to study spalling and deformation associated with tunnelling at depth
}

\author{
TV Garza-Cruz Itasca Consulting Group, Inc., USA \\ M Pierce Itasca Consulting Group, Inc., USA \\ PK Kaiser Laurentian University, Canada
}

\begin{abstract}
For mining at depth or deep caving operations, it is increasingly important to better understand the failure process near underground excavations and, for support design, it is necessary to better anticipate the related deformation characteristics of brittle failing rock.

This paper describes how 3DEC was used to model the rock mass as an assembly of tetrahedral (tet) blocks bonded at their contacts, and to investigate spalling and unidirectional bulking of massive to moderately jointed rock masses by introducing tensile strength heterogeneity at the block contacts. The 3DEC approach differs from particle-based methods in its ability to represent a zero-initial porosity condition, as well as interlocked irregular block-shapes that provide resistance to block rotation (moments) after contact breakage. These processes tend to dominate the rock mass behaviour in low confinement zones near excavations and thus are relevant for both stability assessment and support design.
\end{abstract}

The results of simulations employing this approach are summarised to assist in understanding the growth of fracture patterns and related stress redistribution, as well as deformation around a highly stressed tunnel. Mining-induced stress changes are approximated to simulate the effects of over-mining with an undercut, as typically used in a cave mine.

The model response is found to be consistent with current theories concerning the spalling and bulking of massive rock at depth and with observations made in analogous civil and mining tunnels. However, the results also suggest that data from continuum models with plasticity models may be misleading in terms of extent and deformation in the non-elastic zone.

This paper supports the view that excavation stability in brittle rock types is dominated by tensile or extensional failure processes near the excavation and that bulking enhanced by geometric block-shape factors needs to be considered for support design.

\section{Introduction}

Massive underground mining is becoming ever more prevalent, specifically caving mines at deeper levels, i.e. depths $>1,000 \mathrm{~m}$. The development of cave mine infrastructure in a deep, highly stressed environment that may lead to excavation instability problems, and the way mine development sequencing and cave advance affect the re-distribution of induced stresses on mine infrastructure as mining progresses, need to be considered for support design.

Continuum approaches are very effective in revealing important metrics such as stress (and strain) directions, and their relative magnitudes as mining progresses. However, they are inherently limited when the rock behavior involves mechanisms such as spalling and bulking. In such situations, discontinuum approaches such as discrete element method (DEM) can realistically simulate the initiation and propagation of cracks leading to extension and shear fracturing, as well as the rock mass strength dependency on confinement. Unfortunately, these DEMs are too computationally expensive to be implemented in a large scale caving model. The ability to simulate brittle failure as a dominant failure mechanism at low 
confinement, while the unstable propagation of tensile fractures is inhibited at higher confinement, is of prime importance for adequate stability assessment and support design.

This paper is divided into three main sections. The first section describes the procedure used to model massive, brittle, spalling rock in 3DEC (Itasca Consulting Group, Inc. 2013). The second section deals with the role support pressure plays in rock damage and bulking in the vicinity of a tunnel; elucidating extensional and localised shear failure at block boundaries as the main failure mechanism near tunnel walls; and the development of a high degree of unidirectional bulking at low support pressures. The effect of rock mass reinforcement on the stress fracturing and bulking is not simulated. The third section describes the response of an array of parallel tunnels to a mining-induced stress path that approximates loading and relaxation due to a caving operation.

\section{3DEC model for massive brittle rock}

3DEC was used to simulate the response a deep tunnel under high stresses would have to support pressure and to a caving-induced stress path. 3DEC was selected as it can be used to simulate a massive rock as bonded polyhedral elements (tetrahedral in this case) that can break at their subcontacts as a result of stress concentrations, mimicking the initiation of cracks that can coalesce and/or propagate to fracture the rock-mass. This results in an emergent damage pattern with associated bulking. The 3DEC approach differs from particle-based methods such as PFC3D (Itasca Consulting Group, Inc. 2014) in its ability to represent a zero initial porosity condition, as well as interlocked irregular block-shapes, that provides resistance to block rotation (moments) after contact breakage. These processes tend to dominate the rock mass behaviour in low confinement zones near excavations.

\subsection{DEC sample construction}

A rock mass sample $(18 \times 18 \times 4 \mathrm{~m})$ was constructed by assembling a collection of highly interlocked tetrahedral blocks with an approximate edge length of $0.5 \mathrm{~m}$ using KUBRIX-Geo (Itasca Consulting Group, Inc. 2012) and importing them into 3DEC. The block contacts then were populated with pertinent material properties following a tensile strength distribution to account for intact rock and veins following the methodology described by Garza-Cruz and Pierce (2014) (Figure 1).

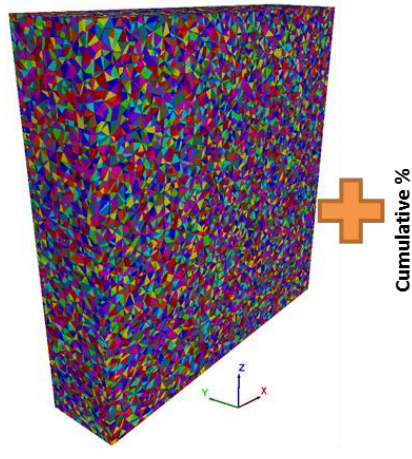

(a)

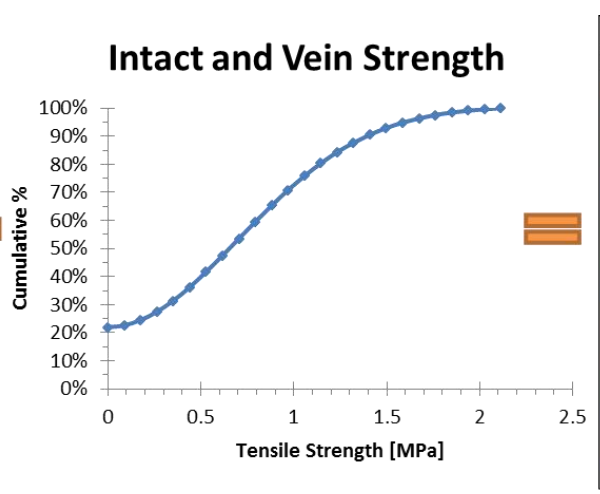

(b)

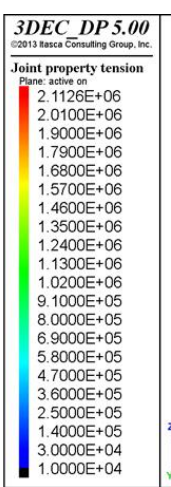

$3.0000 \mathrm{E}+04$
$.0000 \mathrm{E}+04$

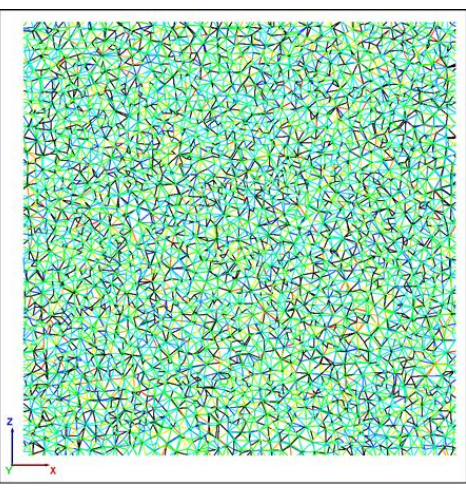

(c)

Figure 1 Synthetic rock mass sample generation procedure; 3DEC $18 \times 18 \times 4 \mathrm{~m}$ sample after trimming $1 \mathrm{~m}$ off all sides (a); tensile strength cumulative distribution for the contacts in the 3DEC model (b); and vertical cross-section through sample showing the block contact tensile strength distribution (c). Block contacts in black have zero tensile strength and cohesion value, and account for $22 \%$ of all contacts

In order to populate a sample, each block contact was assigned a tensile strength value randomly selected from the cumulative distribution of rock tensile strength, and its local cohesion was set to be 2.5 times that tensile strength. This cohesion-to-tensile-strength ratio was based on a sensitivity study in which such 
ratios produced macro unconfined compressive strength (UCS)/tensile strength ratio on the order of 10-20. In all models, the blocks were defined as elastic and zoned with an approximate edge length of $0.5 \mathrm{~m}$. The Young's modulus of the blocks was assumed to be that of the intact rock of interest (50 GPa). The presence of veins and other discontinuities contribute to a reduction of the rock mass Young's modulus that can be estimated through rock mass quality, i.e. geological strength index (GSI). In this study, a rock mass Young's modulus of $11 \mathrm{GPa}$ was assumed and achieved through the selection of corresponding block-contact normal and shear stiffness. The blocks and block-contacts micro-mechanical properties are summarised in Table 1.

\section{Table 1 Elastic block and contact mechanical properties used in the model}

\begin{tabular}{cc}
\hline \multicolumn{2}{c}{ Block properties } \\
\hline Young's modulus & $50 \mathrm{GPa}$ \\
Poisson's Ratio & 0.25 \\
Density & $2,650 \mathrm{~kg} / \mathrm{m}^{3}$ \\
\hline \multicolumn{2}{c}{ Contact properties } \\
\hline Normal stiffness & $105 \mathrm{GN} / \mathrm{m}$ \\
Shear stiffness & $52.5 \mathrm{GN} / \mathrm{m}$ \\
Peak friction angle & $40^{\circ}$ \\
Residual friction angle & $40^{\circ}$ \\
Dilation angle & $10^{\circ}$ \\
Peak tensile strength & Variable - from distribution \\
Residual tensile strength & 0 \\
Peak cohesive strength & $2.5 \times$ tensile strength \\
Residual cohesive strength & 0 \\
\hline Elastic boundary block properties \\
\hline Young's modulus & $11 \mathrm{GPa}$ \\
Poison's Ratio & 0.25 \\
\hline
\end{tabular}

The constructed 3DEC sample was tested under uniaxial compression at a constant strain rate, between frictionless roller boundary conditions (relevant to spalling conditions), exhibiting a compressive strength of $3 \mathrm{MPa}$ and a rock mass Young's modulus of $11 \mathrm{GPa}$. Compressive strength under such conditions is analogous to the damage initiation threshold discussed by Diederichs (2007).

The impact of block size was examined by replicating the construction and testing of a sample made of tetrahedral blocks with approximate edge length of $0.25 \mathrm{~m}$, with no impact on ultimate strength found.

\section{$3 \quad$ Tunnel response at depth}

\subsection{Effect of support pressure on brittle failure near tunnel}

In order to simulate mining of a tunnel at depth under high in situ stresses, the rock mass sample was embedded in an elastic boundary and the model was equilibrated under in situ stress state $\left(\sigma_{\mathrm{v}}=31 \mathrm{MPa}\right.$, $\sigma_{\mathrm{H}}=3^{*} \sigma_{\mathrm{v}}=93 \mathrm{MPa}$, and $\left.\sigma_{\mathrm{h}}=1.6^{*} \sigma_{\mathrm{v}}=50 \mathrm{MPa}\right)$. The Young's modulus of the elastic boundary was set to match that of the rock mass ( $11 \mathrm{GPa}$ ) and its Poisson's Ratio was assumed to be 0.25 . A tunnel aligned with 
the direction of $\sigma_{\mathrm{h}}$ was mined through the 3DEC bonded tet block material with dimensions (Figure 2). Symmetry boundary conditions were used at all vertical boundaries of the model to simulate an array of parallel tunnels at $30 \mathrm{~m}$ intervals.

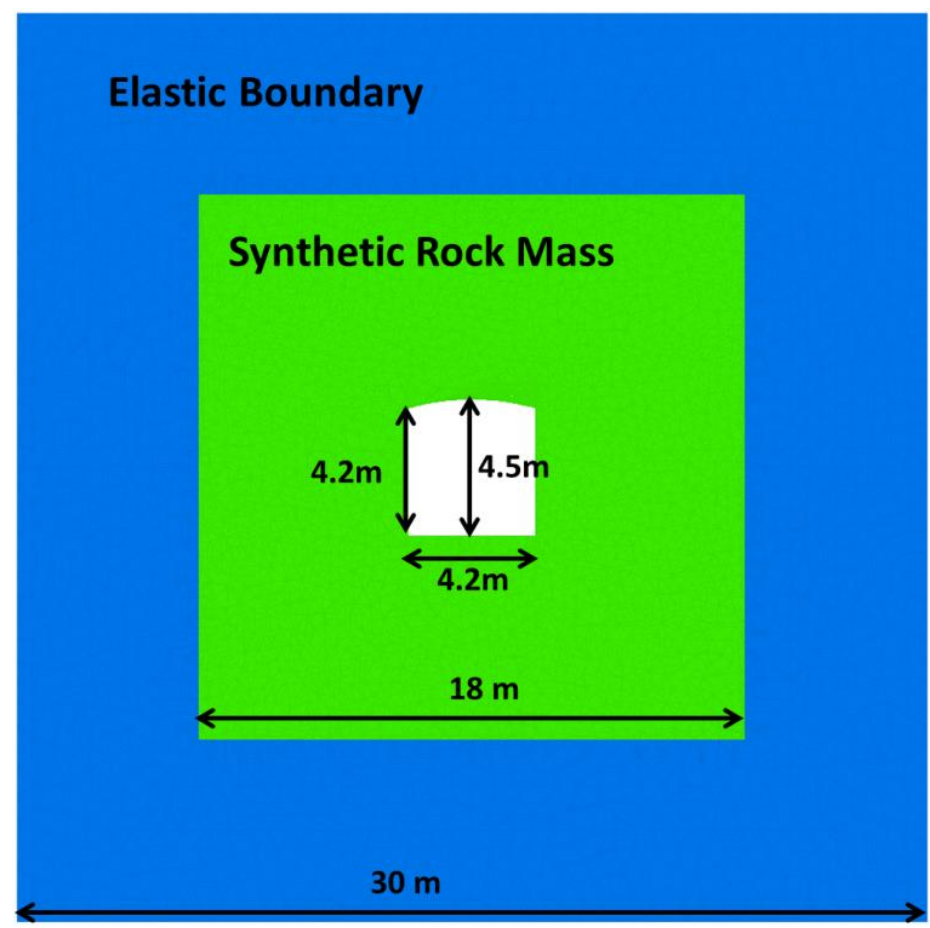

\section{Figure 2 Tunnel mined through a 3DEC bonded tet block material embedded in an elastic boundary representing an array of tunnels at $\mathbf{3 0} \mathrm{m}$ intervals}

To study the tunnel response to support pressure removal, an approximation for 3D effects at the tunnel face, normal stress was applied on the tunnel walls immediately after mining. Such normal stress was incrementally reduced in 18 steps until no pressure was applied to the tunnel walls (the model was allowed to equilibrate in each step), while the rock mass damage development and deformation around the excavation was monitored at each relaxation stage. Figure 3 shows cross-sectional views of the predicted rock mass damage at selected support pressures (colours represent distinct fragments).

Figure 4 shows the associated deformations as a function of distance into the wall (a), and back (b) for four different support pressures. These show high bulking near the excavation in walls and immediate roof, at $<1 \mathrm{~m}$ depth. As the support pressure is decreased, surface parallel fractures start to appear and coalesce to form debonded fragments, resulting in an inner shell of highly damaged ground with a thickness of about 1-2 $\mathrm{m}$ (Figure 5). During this process, block boundaries open due to extensional straining or shear when inclined to the local stress. 
Support pressure $=20 \mathrm{MPa}$

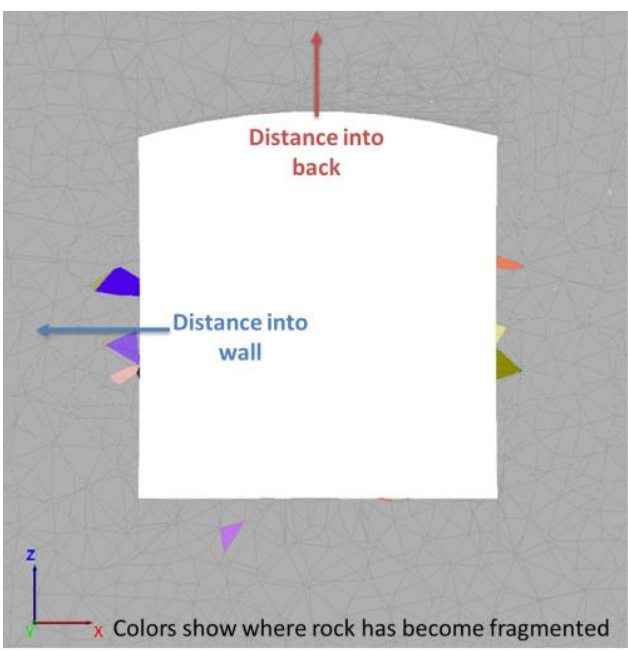

Support pressure $=1 \mathrm{MPa}$

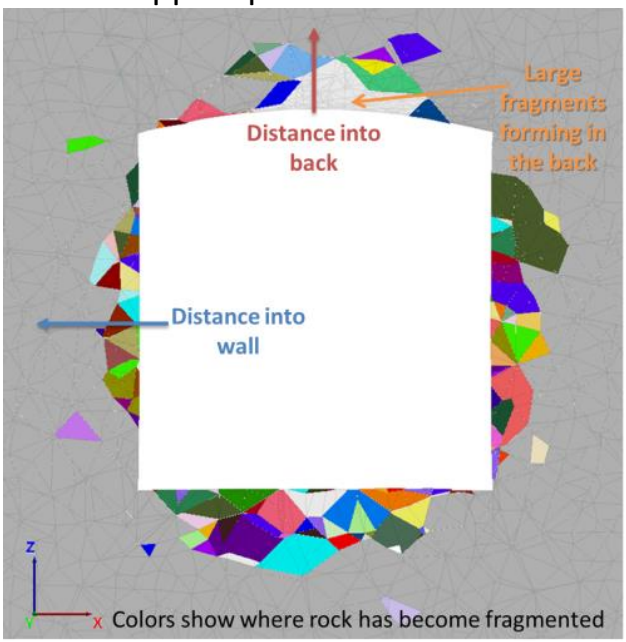

Support pressure $=5 \mathrm{MPa}$

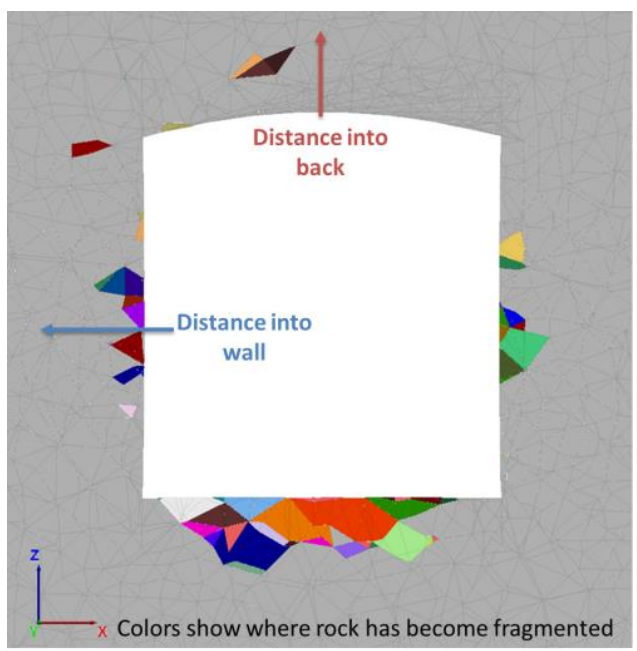

Support pressure $=0 \mathrm{MPa}$

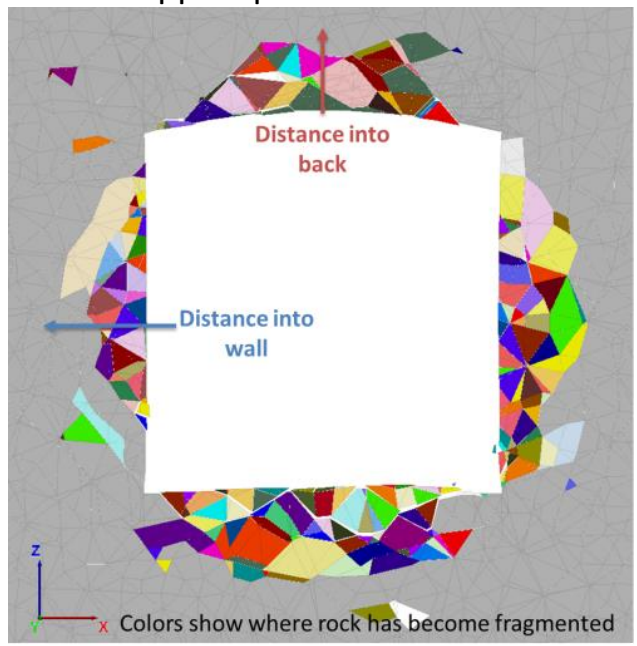

Figure 3 Cross-sectional view of rock mass damage as the support pressure is reduced. Colours indicate distinct fragments 


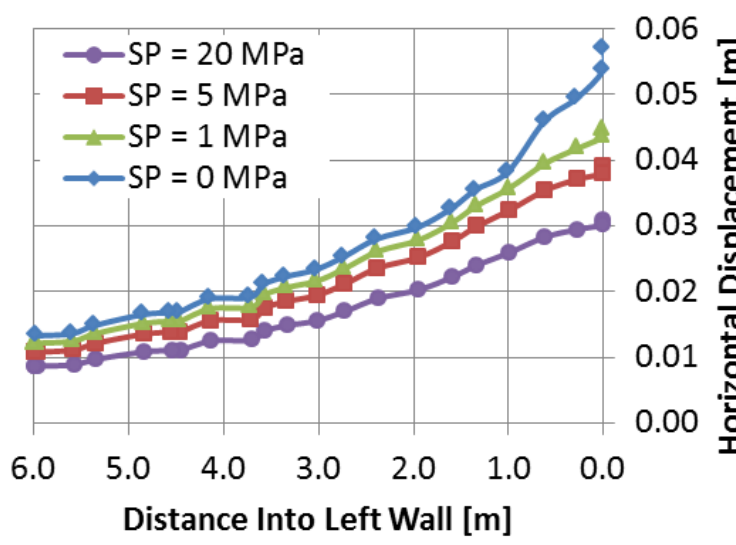

(a)

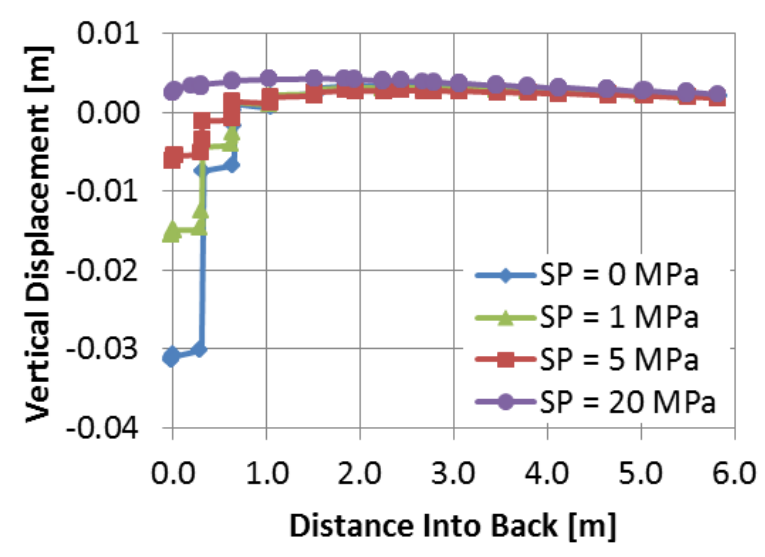

(b)

\section{Figure 4 Displacement profiles $6 \mathrm{~m}$ into the wall (a); and back (b) at four support pressures shown in Figure 3}
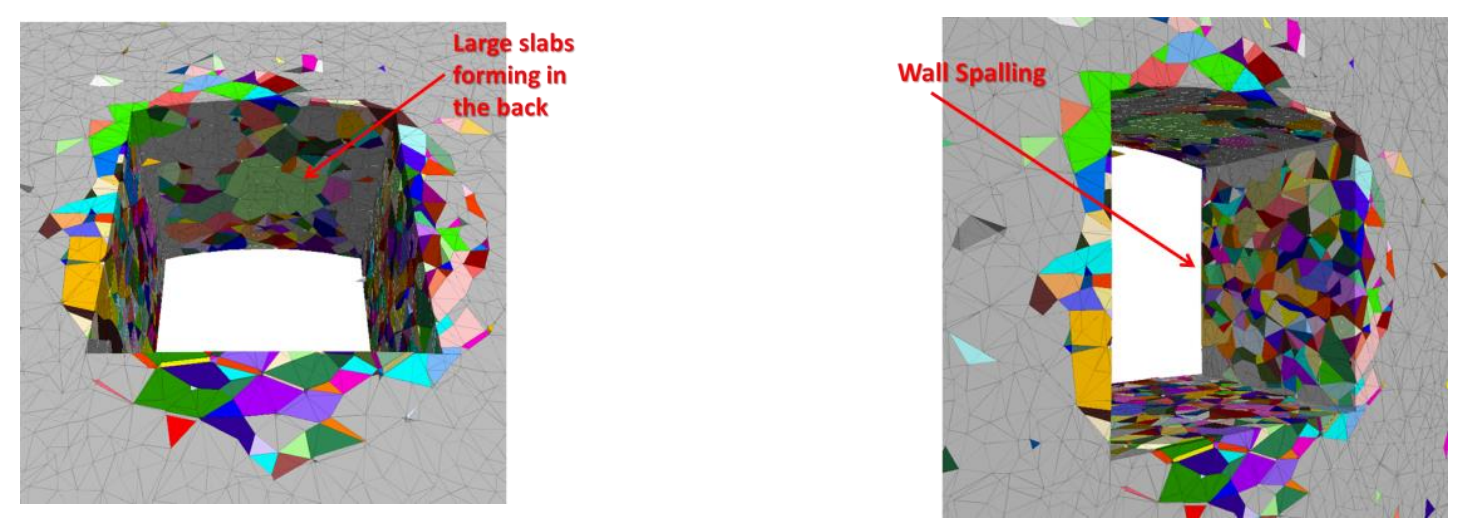

\section{Figure 5 Rock mass damage at a $1 \mathrm{MPa}$ support pressure. Colours indicate distinct fragments, elucidating slab formation by extension failure at block boundaries as the main failure mechanism}

The associated ground reaction curve, shown in Figure 6, reveals that the rate of bulking starts to rise rapidly at a support pressure below about $5 \mathrm{MPa}$, and then increases dramatically below about $1 \mathrm{MPa}$, highlighting a missing component in conventional continuum analysis, i.e. the extreme sensitivity to bulking at low confinement, which adds much deformation to the support. Intense fracturing and deformation at the walls leads to a distinct highly bulked region $(0.5-1 \mathrm{~m})$ where bulking increases substantially, leading to a kinked displacement profile (Figures 4 and 7). The inner shell is approximately demarcated in Figure 7 (fractures with normal displacement $>0.8 \mathrm{~mm}$ are shown as black lines). In the outer shell, flaws are clamped as confinement increases rapidly into the walls. This suggests that the rock mass adjacent to excavations behaves differently than when under confinement, as the main failure mechanism changes from tension to shear (shear through blocks is not simulated for this paper). This is consistent with current theories concerning the spalling and bulking of massive rock at depth (Kaiser et al. 2000; Diederichs et al. 2004; Diederichs 2007; Kaiser 2010; Kaiser et al. 2011; Kaiser 2014).

Although significant damage has occurred in the tunnel back, its arched shape provides a kinematic constraint to downward displacement, preventing the spalled fragments from collapsing into the tunnel. In the immediate tunnel vicinity, confinement has been completely lost, as illustrated by the black regions in Figure 8. However, it rapidly increases to levels higher than $15 \mathrm{MPa}$ at $<2 \mathrm{~m}$ into the wall $(<0.5$ times tunnel width), and $<1 \mathrm{~m}$ into the back ( $<0.25$ times tunnel width). Such rapid confinement build-up allows the rock 
mass to sustain induced stress concentrations as high as $180 \mathrm{MPa}$ (at support pressure $=1 \mathrm{MPa}$ ), and $200 \mathrm{MPa}$ (zero support pressure) into the tunnel back (Figure 8). This observation is highly relevant when selecting bolt lengths in support design.

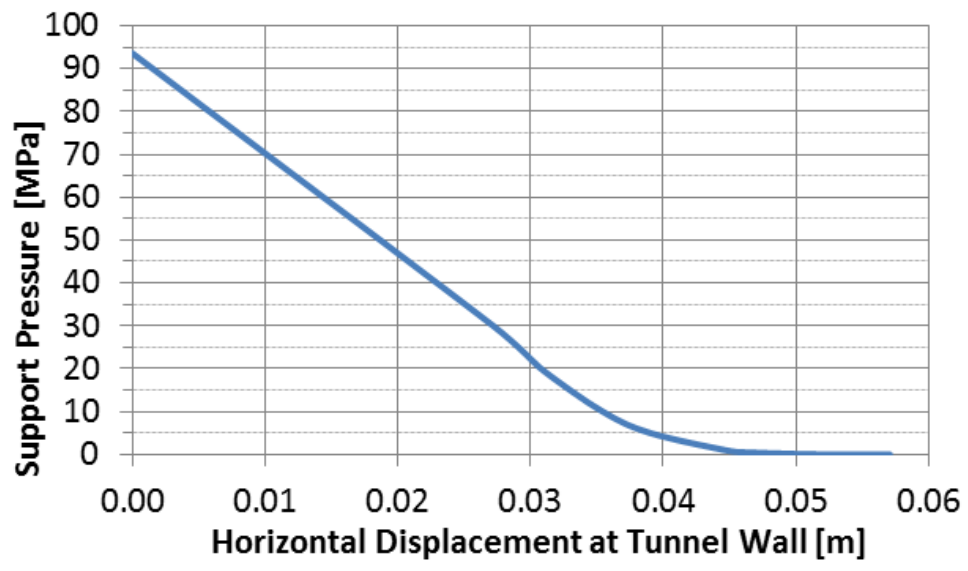

Figure 6 Ground reaction curve showing a dramatic increase in the rate of bulking when support pressure drops below $1 \mathrm{MPa}$

One of the main advantages of using a discontinuum approach is that crucial mechanisms such as spalling and unidirectional bulking may be captured as emergent rock mass behaviour. Continuum models are inherently limited in their ability to simulate such mechanisms and may be misleading with respect to the depth and extent of yield (demanding longer bolts), and with respect to the axial straining of the bolts (permitting use of stiff reinforcements). 
Support pressure $=1 \mathrm{MPa}$

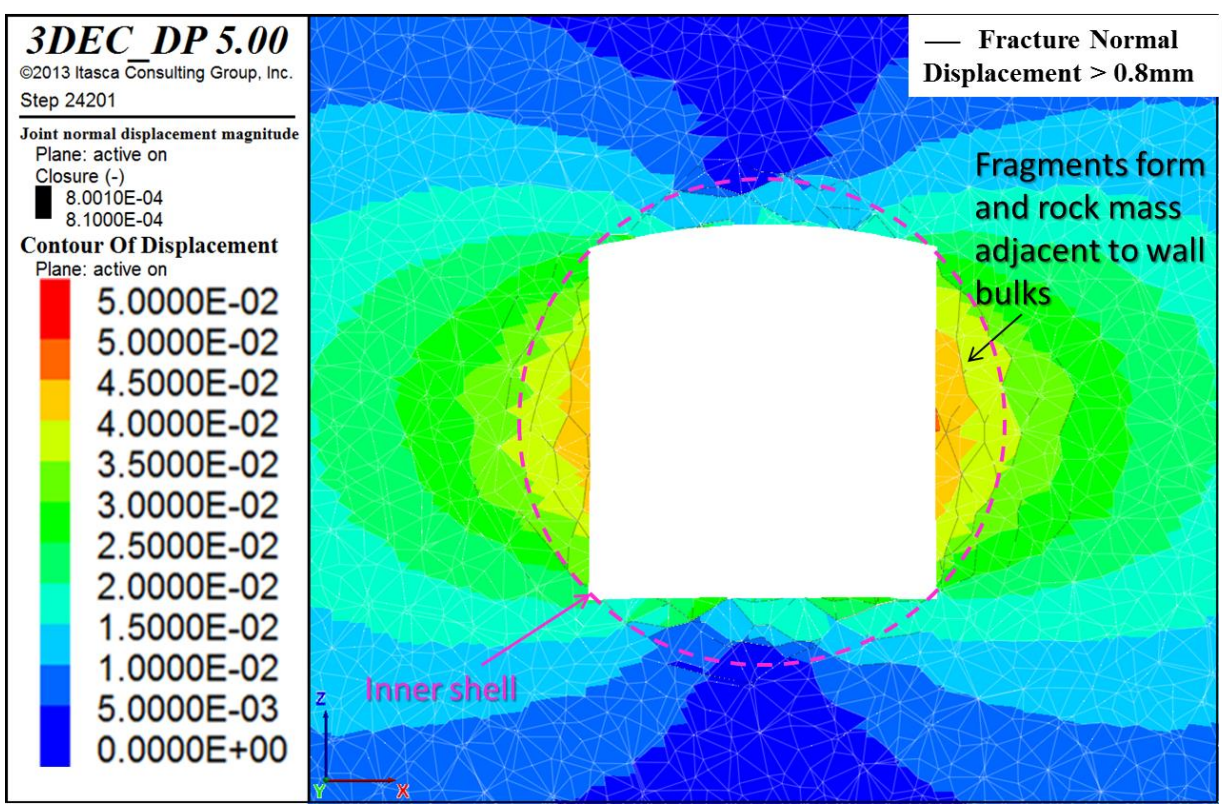

Support pressure $=0 \mathrm{MPa}$

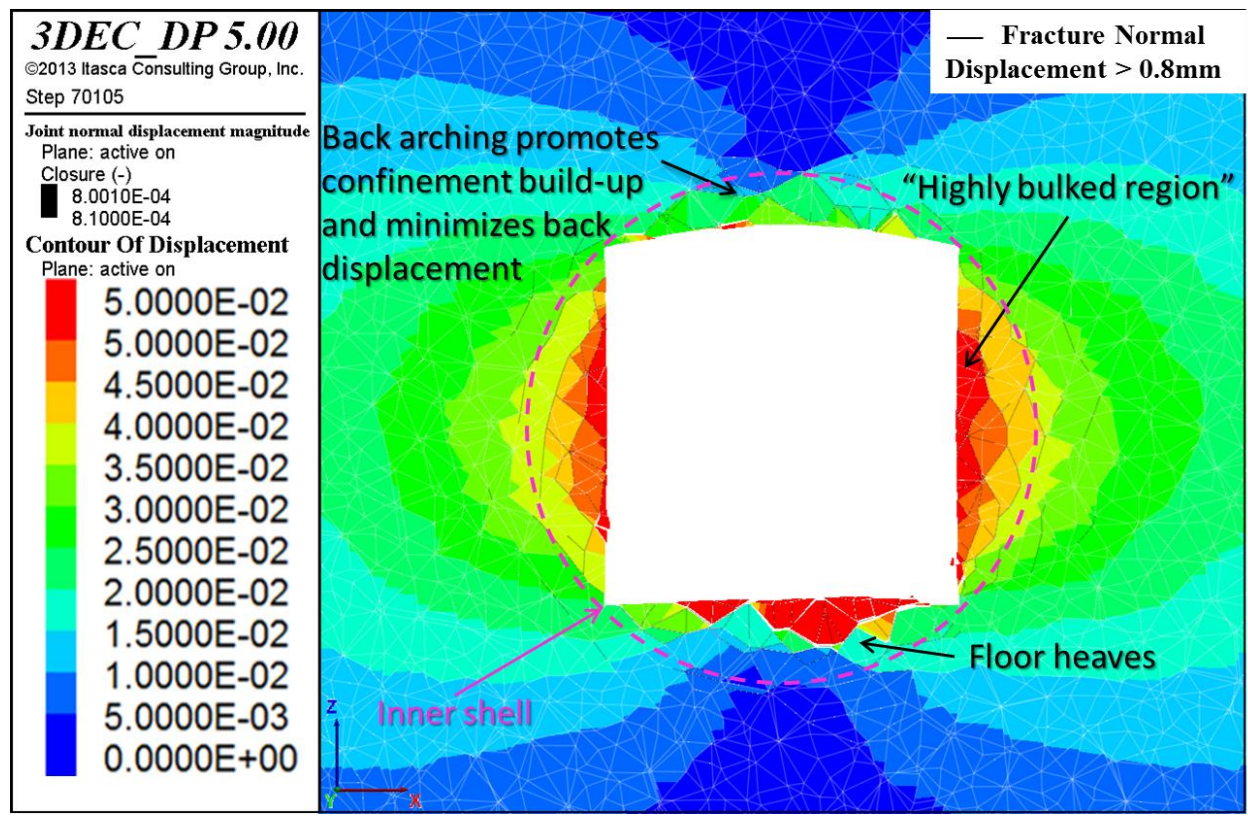

Figure 7 Cross-sectional view of the displacement profile around the excavated tunnel at $1 \mathrm{MPa}$ (top); and zero support pressure (bottom). A distinct highly bulked region can be seen in the immediate wall. The inner shell is approximately demarcated with a dashed circle 
Support Pressure $=0 \mathrm{MPa}$

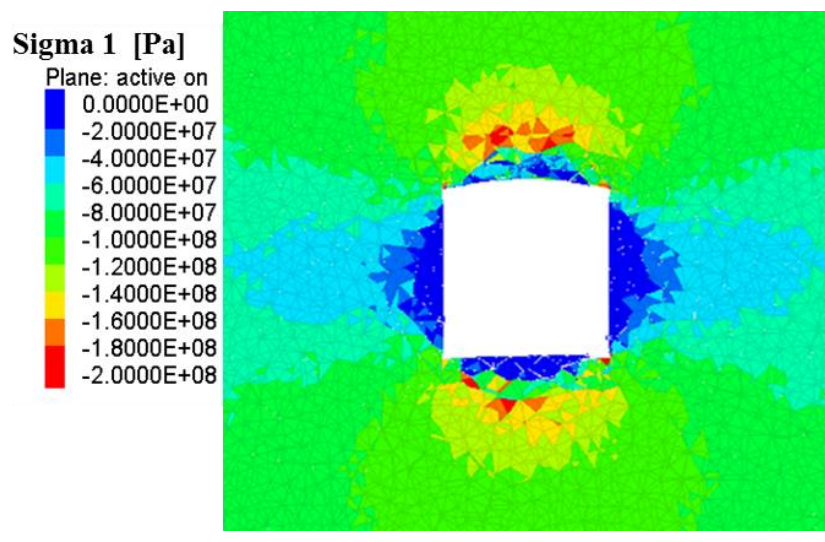

(a)

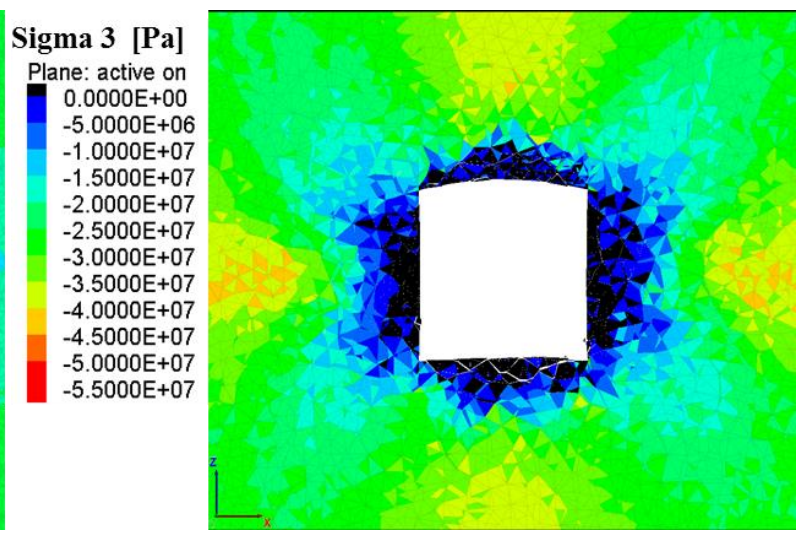

(b)

Figure 8 Major induced principal stress $\sigma_{1}(a)$; and minor principal stress $\sigma_{3}$ or rock confinement (b); in the vicinity of the tunnel with zero support pressure. Negative stresses denote compression

\subsection{Tunnel performance under a caving-induced stress path}

The relaxed tunnel model described in the previous section, support pressure $=0 \mathrm{MPa}$, was used as the initial condition to study tunnel performance when subjected to a caving-induced stress path. Mining-induced stress changes were approximated to simulate the effects of over-mining of the tunnel in a cave mining scenario (Figure 9). The first part of the stress path consisted of loading the model in a quasi-static manner to increase the vertical stress to $55 \mathrm{MPa}$, simulating an increase in abutment stresses as the cave front (or undercut) is incrementally advanced, followed by a relaxation in vertical stress back to $31 \mathrm{MPa}$ simulating the passing over of the cave. In reality, the relaxation in vertical stress is expected to drop to lower levels of vertical stress; possibly as low as $5 \mathrm{MPa}$. The relaxation level presented is of a schematic nature and does not reflect an actual case example.

\section{Caving-Induced Stress Path}

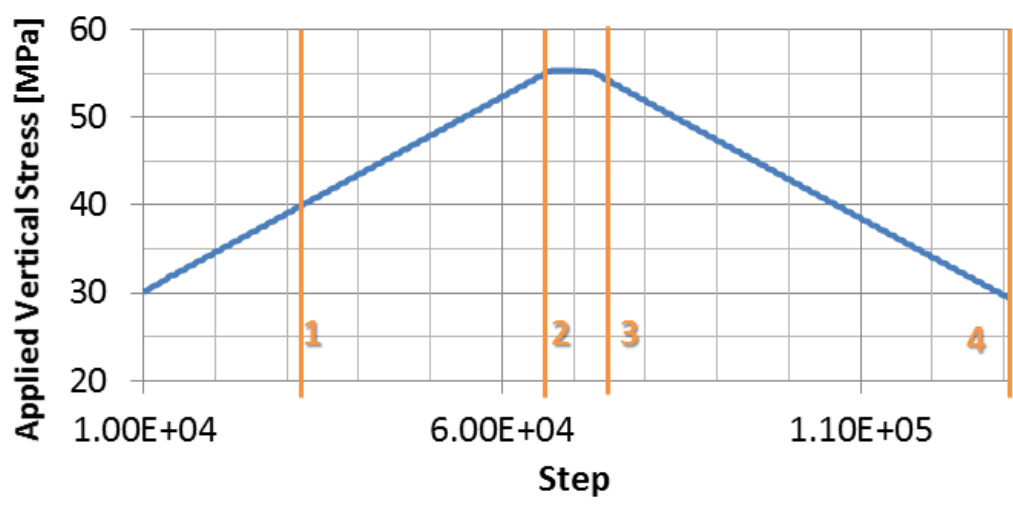

Figure 9 Schematic of caving-induced stress path followed to model the tunnel performance under over-mining in a cave mining scenario 
Figure 10 shows the displacement profile and approximate inner shell limits at the four stages indicated by orange lines in Figure 9. As soon as loading on the tunnel increases, new tensile fractures form and coalesce in the vicinity of the corners of the tunnel forming a more circular and stable inner shell configuration (stage 1, Figure 10). This promotes confinement build-up into the tunnel walls. Further compression of the tunnel (up to $55 \mathrm{MPa}$ ) results in no dimensional change of the limits in either the inner shell or the highly bulked region (stage 2, Figure 10). Although the highly bulked region limits do not change, it continues to bulk at a high rate, due to a geometrical bulking effect of non-fitting blocks (Figure 12). At the end of the loading cycle (stage 2, Figure 10), confinement increases exhibiting a high gradient away from the tunnel periphery. It allows for induced stresses of the order of $100 \mathrm{MPa}$ to concentrate near the walls (to a distance of about 0.5 times tunnel width) and $200 \mathrm{MPa}$ above and below the tunnel (Figure 13).

This has important implications in the support design of excavations at high depths under large stresses, as it shows how the modelled rock mass behaves in a low-strength spalling-type manner at low confinement, with strength rapidly increasing with confinement into the wall. This suggests that the pillar-core strength may be significantly underestimated when designed by methods that do not take into account the change in rock mass failure mode with confinement.

As the tunnel model is unloaded back to about $31 \mathrm{MPa}$, the confinement drops at a faster rate than the induced major principal stress $\sigma_{1}$ (Figure 13), promoting tensile cracks to initiate, propagate and coalesce, which in turn causes the inner shell to grow (Figure 11). The unloading process causes minor additional bulking in the highly bulked region, but it deepens the bulking zone. Thus, bulking of the newly fractured rock mass in the expanding inner shell pushes the previously bulked material into the excavation (stage 4, Figure 11). This can be seen in Figure 12, where at stage 4 the slope of the displacement profile outside of the highly bulked region steepens. This translates the portion of the curve corresponding to the highly bulked region upwards.

Again, this has important implications for excavation stability assessment and support design. First, these models show that the unloading cycle does more damage than the loading cycle as a larger volume of rock is entering the inner shell (the zone of low confinement that is prone to extensional failure). As a consequence, the support will be more severely strained during unloading (relaxation) than during loading. This aspect of relaxation driven straining is evident from conventional, continuum models and is seen as a critical support design element. Furthermore, relaxation related rock mass degradation and straining is not captured by any rock classification system. Hence, support systems designed on the basis of rock classification may be suitable for tunnel construction, but are likely inappropriate for situations where mining induced straining due to fracturing and related geometric bulking is to be expected. 
Loading Stages
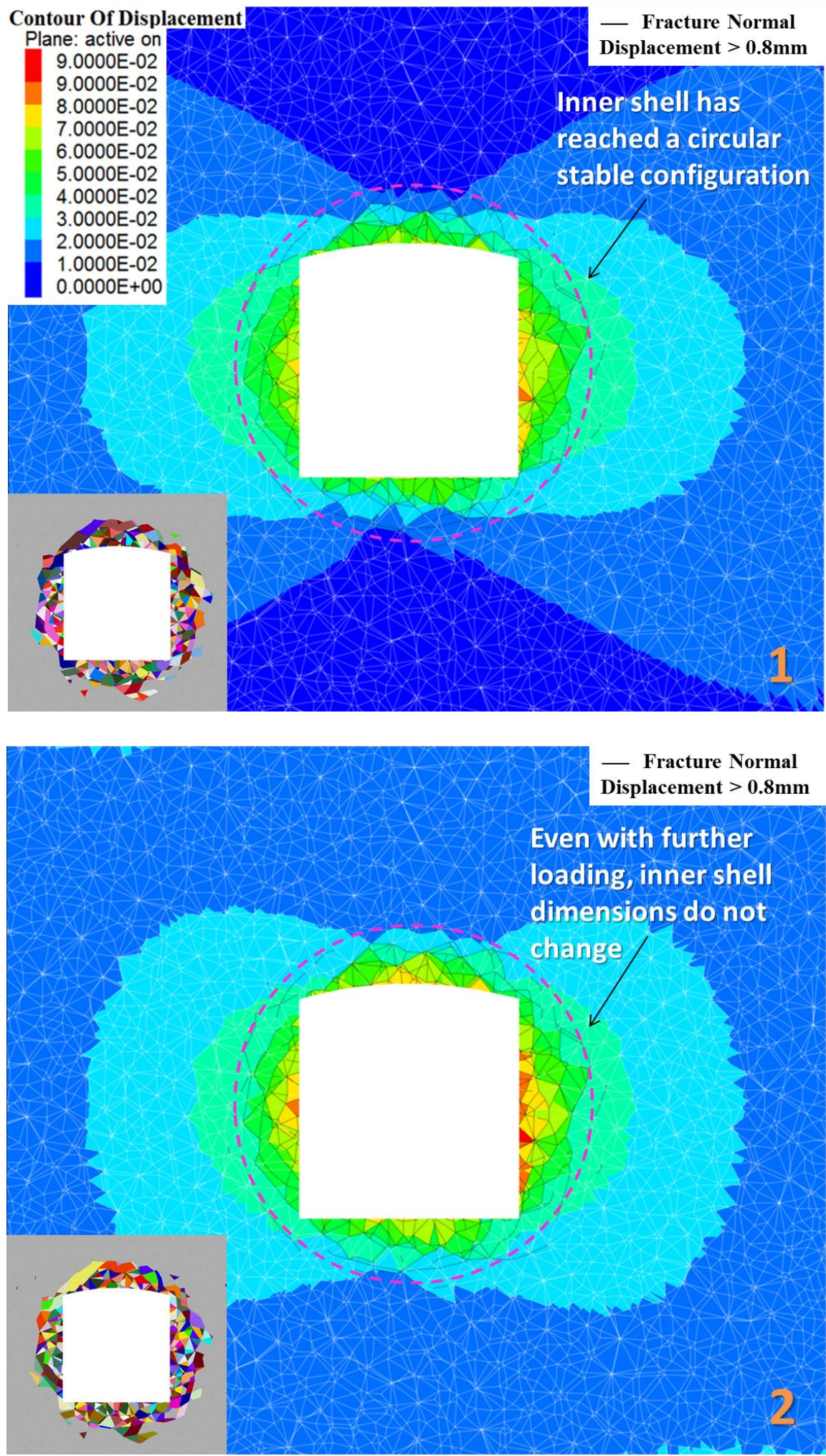

Figure 10 Cross-sectional view of the displacement profile around the excavated tunnel at loading stages 1 and 2 shown in Figure 9. Corresponding rock mass fragmentation is also shown (colours indicate distinct fragments). The inner shell is approximately demarcated with a dashed circle 

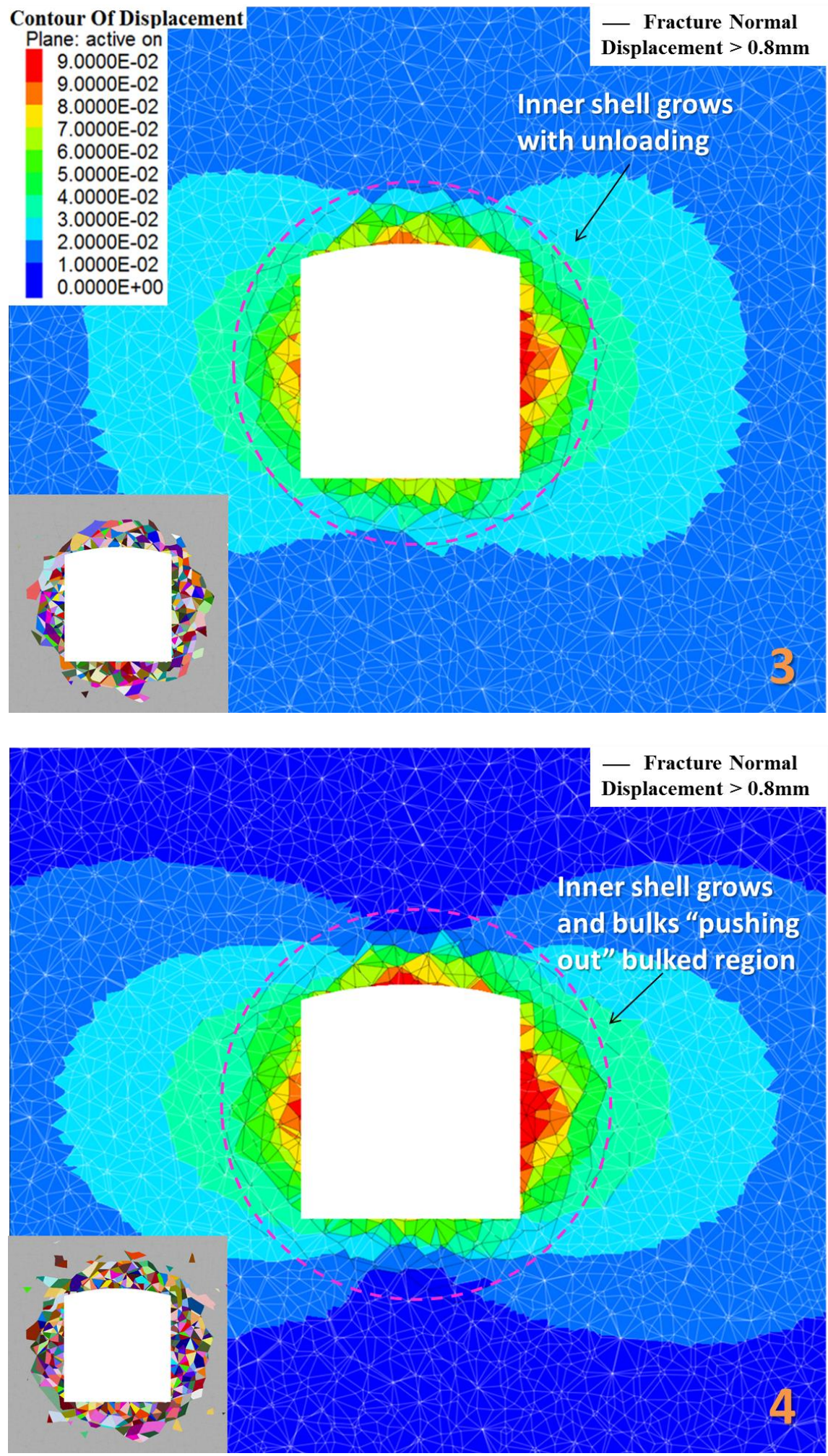

Figure 11 Cross-sectional view of the displacement profile around the excavated tunnel at unloading stages 3 and 4 shown in Figure 9. Corresponding rock mass fragmentation is also shown (colours indicate distinct fragments). The inner shell is approximately demarcated with a dashed circle 


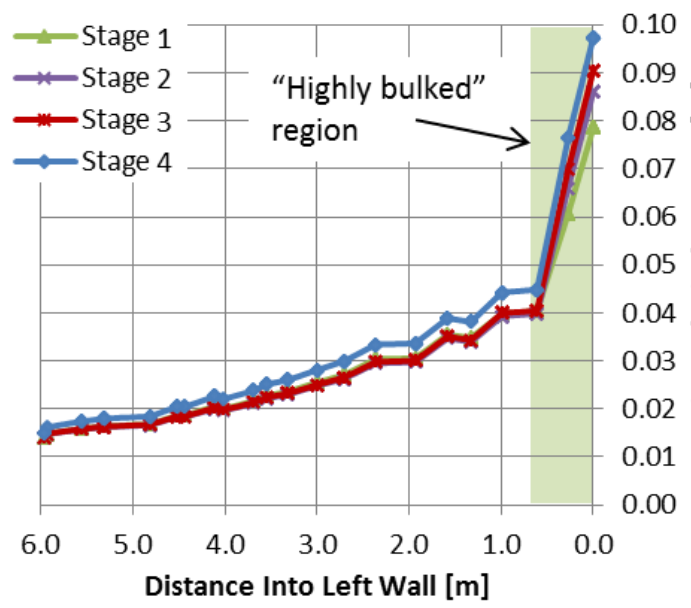

(a)

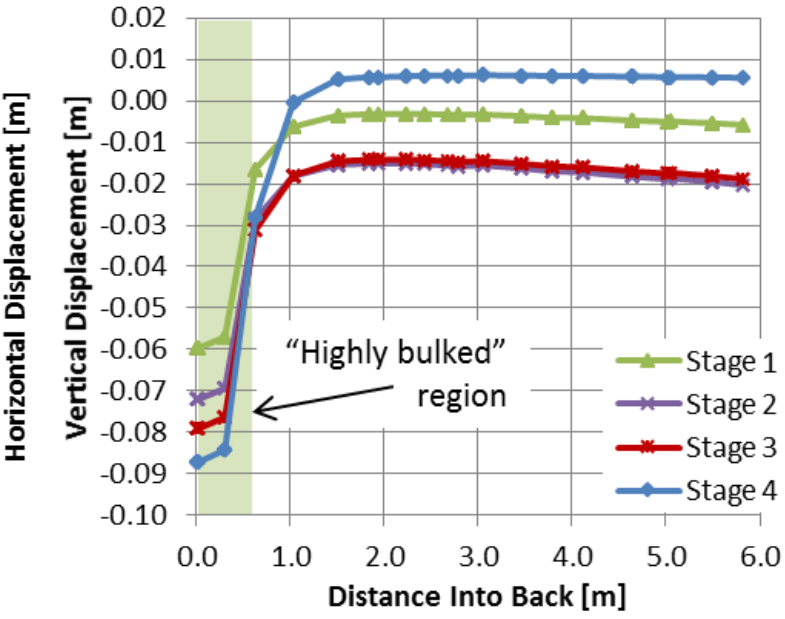

(b)

Figure 12 Displacement profile $6 \mathrm{~m}$ into the wall (a); and back (b) at the different loading and unloading stages shown in Figure 9

Loading to $55 \mathrm{MPa}$ (stage 3)
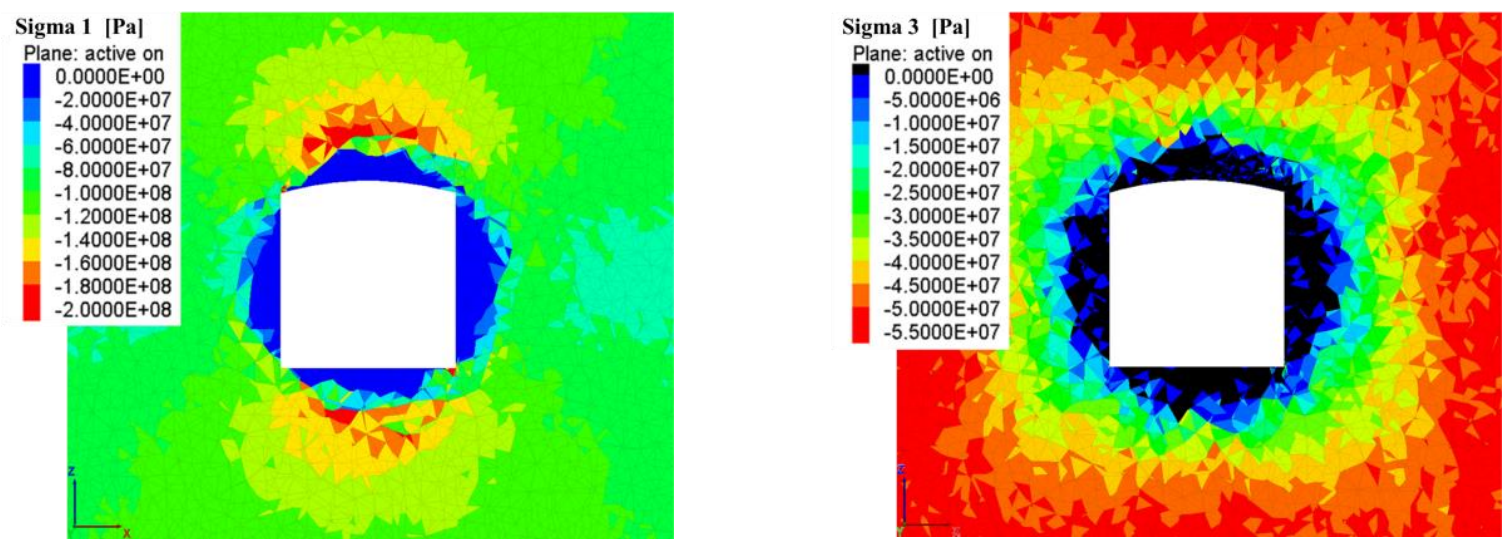

Unloading to $31 \mathrm{MPa}$ (stage 6)

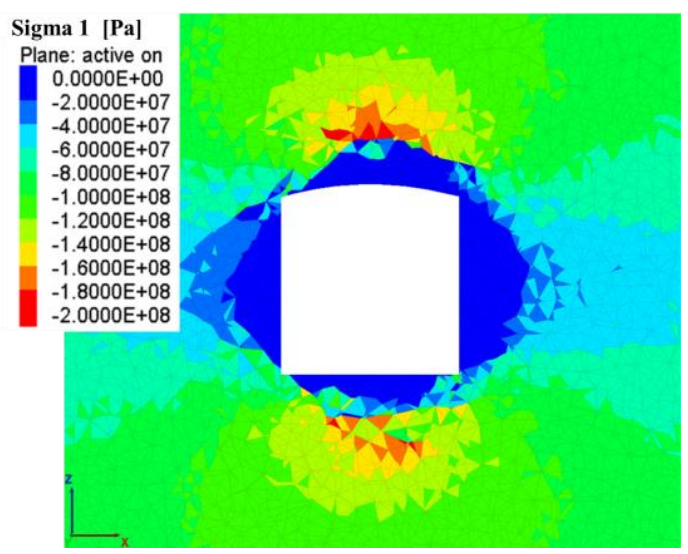

(a)

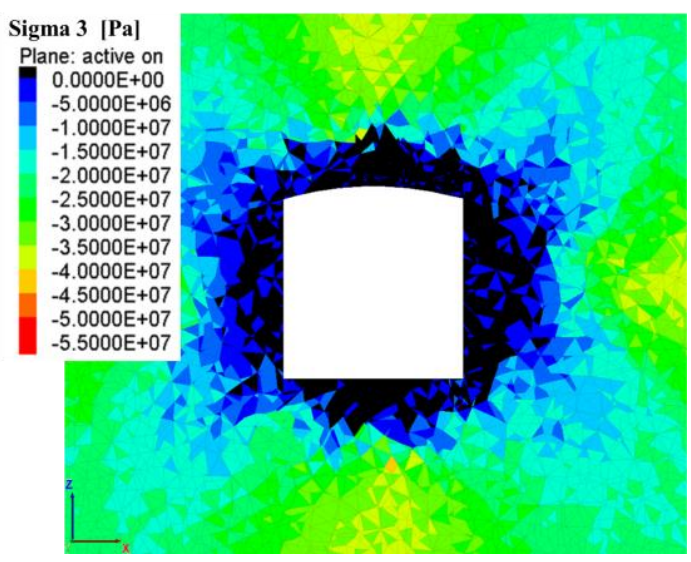

(b)

Figure $13 \quad \sigma_{1}$ induced stress (a); and confinement (b); in the vicinity of the tunnel after the tunnel has been loaded to $55 \mathrm{MPa}$ (top); and unloaded to $31 \mathrm{MPa}$ (bottom); corresponding to stages 2 and 4 in Figure 9, respectively 
Contrary to common expectations, the results presented here suggest that deep excavations in brittle failing rock masses, subjected to sufficiently large stresses causing damage, may experience the largest amount of damage when the vertical stresses decrease, i.e. when the rock mass is being relaxed. Due to the associated rapid rate of confinement drop, compared to induced stress drop, support will be more strained during relaxation than during loading.

\section{Conclusions}

An approach to the study of spalling and unidirectional bulking of massive rock masses around tunnels has been illustrated. The method employs bonded tet block models in 3DEC. The model results show that the behaviour of brittle rock masses close to and far from an excavation differ significantly, as the failure mechanism changes from predominantly tensile or extension fracturing (spalling) to a confined shear. Conventional modelling techniques involving constitutive models that do not take into account the rock mass strength sensitivity to confinement, may lead to misleading results with respect to depth and extent of fracturing/yield, as well as the related rock mass bulking. This may lead to erroneous support designs as the modelled deformation patterns or strain fields may be underestimated.

The model results elucidated that as support pressure is lowered in a tunnel, a well-defined inner shell of low confined, stress fractured rock develops in the periphery of the tunnel as a result of brittle failure. Furthermore, a highly bulked region within such an inner shell has been identified, in which most of the bulking takes place. During the relaxation of the tunnel, the associated ground reaction curve highlights a missing component in conventional continuum analysis, i.e. the extreme sensitivity to bulking adding much deformation at low support pressures. Once a stable inner shell has developed, confinement build-up is promoted in the outer shell, and further loading (as a result of caving advance) does not significantly change the inner shell limits. However, it promotes further bulking in the highly bulked region as a result of a geometric bulking effect. It is during unloading of the system, consisting of a damaged inner shell and an adjacent well-confined outer shell (due to caving overpass and upward propagation), that further tensile damage is incurred. This is a result of rapid confinement loss, leading to the inner shell being pushed into the excavation as the size of the relaxation related damage zone increases. In other words, during the unloading stage, further bulking of the highly bulked region does not take place, it is rather pushed out by the bulking of the newly damaged ground between the bulked and undamaged ground. These mechanisms modify the stress and strain field around the excavation, and thus affect support design. The implications are that rock mass classification systems are not suitable for support design when these mechanisms dominate the support behaviour. Brittle failure modelling, as presented here, should be considered for both stability assessment and support design.

\section{Acknowledgement}

This research was partly supported by the Centre for Excellence in Mining Innovation through its Rio Tinto Centre for Underground Mine Construction.

\section{References}

Diederichs, MS 2007, 'The 2003 Canadian Geotechnical Colloquium: Mechanistic interpretation and practical application of damage and spalling prediction criteria for deep tunnelling', Canadian Geotechnical Journal, vol. 44, pp. 1082-1116.

Diederichs, MS, Kaiser, PK \& Eberhardt, E 2004, 'Damage initiation and propagation in hard rock during tunnelling and the influence of near-face stress rotation', International Journal of Rock Mechanics and Mining Sciences, vol. 41, no. 5, pp. 785-812.

Garza-Cruz, TV \& Pierce, M 2014, 'A 3DEC Model for Heavily Veined Massive Rock Masses', Proceedings of the 48th US Rock Mechanics/Geomechanics Symposium, American Rock Mechanics Associated, Alexandria.

Itasca Consulting Group, Inc. 2012, KUBRIX-Geo, Itasca Consulting Group, Inc., Minneapolis, http://www.itascacg.com/software /kubrix-geo

Itasca Consulting Group, Inc. 2013, 3DEC - Three-Dimensional Distinct Element Code, version 5, Itasca Consulting Group, Inc. Minneapolis, http://www.itascacg.com/software/3dec.

Itasca Consulting Group, Inc. 2014, PFC3D - Particle Flow Code in Three Dimensions, version 5, Itasca Consulting Group, Inc., Minneapolis, http://www.itascacg.com/software/pfc 
Kaiser, PK 2010, 'How highly stressed brittle rock failure impacts tunnel design', Proceedings of Eurock 2010, Taylor \& Francis Group, London.

Kaiser, PK 2014, 'Deformation-based support selection for tunnels in strainburst-prone ground', M Hudyma \& Y Potvin, Proceedings of the Seventh International Conference on Deep and High Stress Mining, Sudbury, 16-18 September 2014, Australian Centre for Geomechanics, Perth, pp. 227-240.

Kaiser, PK, Diederichs, MS, Martin, CD, Sharp, J \& Steiner, W 2000, 'Underground works in hard rock tunneling and mining', Proceedings of GeoEng2000, Technomic Publishing Co., Lancaster, pp. 841-926.

Kaiser, PK, Kim, B-H, Bewick, R \& Valley, B 2011, 'Rock mass strength at depth and implications for pillar design', Mining Technology, vol. 120, no. 3, pp. 170-179. 